\title{
Complex Post Traumatic Stress Disorder (PTSD) in Defilement: Case Report
}

\author{
D. A. Kokonya ${ }^{1}$, W. M. Kuria², F. A. Ong'echa1, J. M. Mburu², D. M. Ndetei ${ }^{2}$ \\ ${ }^{1}$ Ministry of Health, Nairobi City, Kenya \\ ${ }^{2}$ Department of Psychiatry, College of Health Sciences, University of Nairobi, Nairobi City, Kenya \\ Email: ${ }^{*}$ dkokonya@yahoo.com
}

Received 3 April 2014; revised 2 May 2014; accepted 1 June 2014

Copyright @ 2014 by authors and Scientific Research Publishing Inc.

This work is licensed under the Creative Commons Attribution International License (CC BY). http://creativecommons.org/licenses/by/4.0/

(c) (i) Open Access

\section{Abstract}

We report a case of the debilitating and lifelong complex post traumatic stress disorder. Data on rape/defilement-related complex post traumatic stress disorder (PTSD) is rare due to low reporting rates and misdiagnosis in Kenya. Childhood complex PTSD is compounded by its symptomatic overlap with rape trauma syndrome (RTS) and attention deficit hyperactivity disorder (ADHD). This case demonstrated the difficulties involved in making the correct diagnosis while at the same time it brought to the fore clearly the features of complex PTSD as opposed to ordinary PTSD. Strengths in management depended on making appropriate diagnosis based on concerted efforts by clinicians, comprehensive care, team work, sensitivity to age and sex, winning trust of the child and the care taker among others and bearing in mind the in-ward handling of the trauma by the rape/defilement victims. This case shared a lot with other cases of complex PTSD in its presentation, course of illness, diagnosis and response to management protocol instituted yielding positive results. Using the lessons learnt from this case, her response was satisfactory based on her improved social and occupational functioning. The patient continues to respond well to treatment to date, bearing in mind that her presentation and age within a dysfunctional family background did not offer good prognosis, especially if the management and social support system will not be steadfast and innovative.

\section{Keywords}

Defilement, Complex PTSD, ADHD, RTS, Extreme Stress, Psychiatric Morbidities

\footnotetext{
${ }^{*}$ Corresponding author.
} 


\section{Introduction}

According to Dr. Judith Herman of the Harvard University (1997), complex post traumatic stress disorder describes the symptoms of long-term or prolonged trauma, not adequately defined by ordinary PTSD. The rape/ defilement victim's experiences in complex PTSD constitute a collection of symptoms described as rape trauma syndrome (RTS) and posttraumatic stress disorder (PTSD). Complex PTSD (also referred to as "disorder of extreme stress") is found among individuals who have been exposed to prolonged traumatic circumstances, especially during childhood and particularly childhood sexual abuse. Biochemically, demonstrated changes in complex PTSD include strong response by amygdala \& hippocampus (link fear \& memory). Furthermore, position emission tomographic (PET) studies show damage to speech and language centres and the associative pathways in the brain due to prolonged and intense trauma. In addition, developmental research demonstrates that huge brain and hormonal changes occur as a result of early life, prolonged traumas which contribute to difficulties with memory, learning, and regulating impulses and emotions. The prevalence rate of PTSD in the USA associated with sexual molestation, physical attack, threats with weapons and physical abuse was approximately about $54.0 \%$ in the year 1999 [1]. Defilement, defined as any unwanted intercourse or penetration (vaginal, anal, or oral) obtained by force, threat of force, or when the victim is an under-age and unable to consent [2]-[4], while post traumatic stress disorder is defined as the human response to overwhelming life experience as an anxiety disorder and an illness of the mind [5]. Studies have shown that most $(66.0 \%)$ of the female commercial sex workers in the United States of America had been sexually abused by their fathers or father-figures and one in every five children would be sexually abused by the $18^{\text {th }}$ birthday, of whom $85.0 \%$ would be abused by adults known to them.

Other studies (1984 \& 1999) showed that an estimated 683,000 women in the United States of America suffered sexual assault annually, of whom, about 33.0\% subsequently developed PTSD at one stage of their lives [6]-[8]. More evidence showed that a year later after sexual assault, the survivors of the ordeal were likely to develop serious psychiatric morbidities including major depression, substance abuse, generalized anxiety, obsessive-compulsive disorder and post-traumatic stress disorder [9]. In the recovery phase of complex PTSD, the rape/defilement victims experienced guilt, shame, fear, anxiety, tension, crying spells, an exaggerated startle response, depression, anger (both generalized and specifically towards men), discomfort in social situations, impaired memory and concentration and rapid mood swings [10] [11]. In spite of the likelihood of developing rape/ defilement-induced psychiatric morbidities, the majority $(60.0 \%-75.0 \%)$ of the victims of sexual assault in the United States of America did not seek mental health services [12] [13]. Other studies showed that white women were more likely to seek mental health services while African American women were more likely to turn to their families and friends for assistance than formal health systems [14]. Unlike the common PTSD suffered by many traumatised people, complex PTSD is characterised by prolonged trauma, difficulties with memory, learning and regulating impulses and emotions. The victim is likely to be from a disruptive, abusive home/family environment that did not foster healthy interaction. This condition affects the brain especially among children leading to hormonal changes which contribute to severe behavioural difficulties (impulsivity, aggression, sexual acting out and self-destructive actions). Other features included emotional regulation difficulties (intense rage, depression and panic) and mental difficulties (such as extremely scattered thoughts, dissociation, and amnesia), all of which were exhibited by this case. Treatment often takes much longer period compared with the regular PTSD, it may progress at a much slower rate and it requires a sensitive and structured treatment programme delivered by a trauma specialist [15]-[18].

\section{Case Report}

A 13-year-old school girl was referred from Thika district hospital, about $45 \mathrm{~km}$ East of Nairobi, to the weekly psychiatric clinic at the Kenyatta National Referral and Teaching Hospital (KNH), Nairobi, in February 2002. She presented herself with a history of 3 years of lack of concentration and decline in school performance, regression in behaviour, enuresis, hyperactivity, talkativeness, temperamental behaviour and experiencing nightmares, disinhibition, poor eye contact and restlessness. A provisional diagnosis of attention deficit hyperactivity disorder (ADHD) had been made and treatment initiated with methylphenidate (Ritalin) $5 \mathrm{mg}$ tablets once a day and imipramine (Tofranil) $25 \mathrm{mg}$ tablets nocte.

Computerised tomography (CT) scan of the brain showed only blunting of the anterior horns of the ventricles that resolved spontaneously two years later. X-rays of the hands, spine and head were normal and the venereal 
disease research laboratory (VDRL) test for syphilis was negative as well as thyroid function tests, haemogram and urinalysis. Antibody test for Toxoplasma gondi was also negative. The patient was the last of four siblings, all of whom were alive and well. She was brought up by a foster father and a biological mother (divorced the patient's biological father in the patient's early childhood). She had poor relationship with the foster father and an acrimonious one with the mother because of the mother's lack of psychosocial support when she was defiled.

She was defiled in 1998 when 9 years and in 2003 at 14 years of age by different but close family members who issued threats to her life and they promised dire consequences if she ever disclosed the defilement to any other person. The mother rebuffed the daughter's attempt to confide the experiences in her and so, she became withdrawn, hostile to the mother and later, she disclosed it to the grandmother subsequent to which they bonded closely.

A diagnosis of complex PTSD due to multiple defilement episodes was made in June 2004 at 15 years of age when the patient finally revealed her experiences to the clinicians. The instruments used in the assessment included the ccomplex PTSD checklist (Dr. Judith Herman, Harvard University, 1997), DSM IV-TR (2002) diagnostic criteria for PTSD, ADHD [19] and problems related to child abuse or neglect and the Rape Victim Advocates (RVA) checklist for rape trauma syndrome (RTS) [20]-[22]. The patient's school performance was assessed using the department of psychiatry, University of Nairobi's questionnaire on the "child's social \& school functioning”. Her diagnosis was based on clinical findings that were deeper than ordinary PTSD. Her treatment was changed and paroxetine hydrochloride (seroxat) $20 \mathrm{mg}$ daily started, yielding dramatic and positive improvements in her social and occupational functioning after three years compared to baseline findings. Alongside pharmacotherapy, the patient benefited from cognitive behavioural (CBT) (mainly for stress relief), exposure therapy, mainly imaginative and to a lesser extent, in vivo (for emotional component) and brief psychodynamic psychotherapy to address the child's unconscious mental contents and conflicts to alleviate the effects of the psychotrauma and for the child to explore the meanings of psychoraumatic responses in the complex situation.

\section{Findings}

\subsection{DSM IV Diagnostic Criteria for Complex PTSD}

The patient was assessed for the presence of PTSD soon after she revealed her experience in June 2004, almost seven years after the first defilement ordeal and approximately a year after the second one. The child scored highly (20/23) on the DSM IV-TR (2002) PTSD criteria that ruled out RTS and ADHD, particularly for exposure, confrontation with and undergoing defilement (2/2), re-experiencing the ordeal (5/5), arousal (5/5) and prolonged (over three years) duration of disturbance (1/1). Others included avoidance of stimuli (5/7) and significant clinical impairment in social and occupational functioning (2/3). The complex PTSD diagnosis was made on the basis of duration, repetition of trauma (repeated defilement) severity of and wide spectrum of symptoms beyond the ordinary PTSD while the rape victims advocates (RVA) was consistent with the child's submissions for rape and clinical findings.

\subsection{Child Assessment Results}

The patient was followed up and managed at the Kenyatta National Hospital's psychiatric clinic for three years and assessments were conducted at baseline in February, 2002 and June, 2004. The assessments were conducted by the same teachers at the same school. The assessments revealed general improvement in academic performance and social functioning which were corroborated with clinical outcomes and family reports. A positive trend emerged in her academic performance, improvement in reading and writing skills. She also improved in social performance except for shame, guilt and anger. Adequate contact with the family had been on for three years between the teachers and the family and the family and the therapists (Figure 1).

The patient's average score of marks in class per term showed a slight improvement in her academic position. She demonstrated the highest consistency and narrowing of the ranges of her class positions from first to third term in the year 2004. A conversion of the term class positions into a scatogram produced a line of about $10^{\circ}$ gradient demonstrating slow but sure path of recovery. The onset of academic consistency and improvement in class positions was also noted to have coincided with the year (2002) of the start of her psychiatric care at KNH and it was maintained up to the end of the year 2004 (Figure 1). 


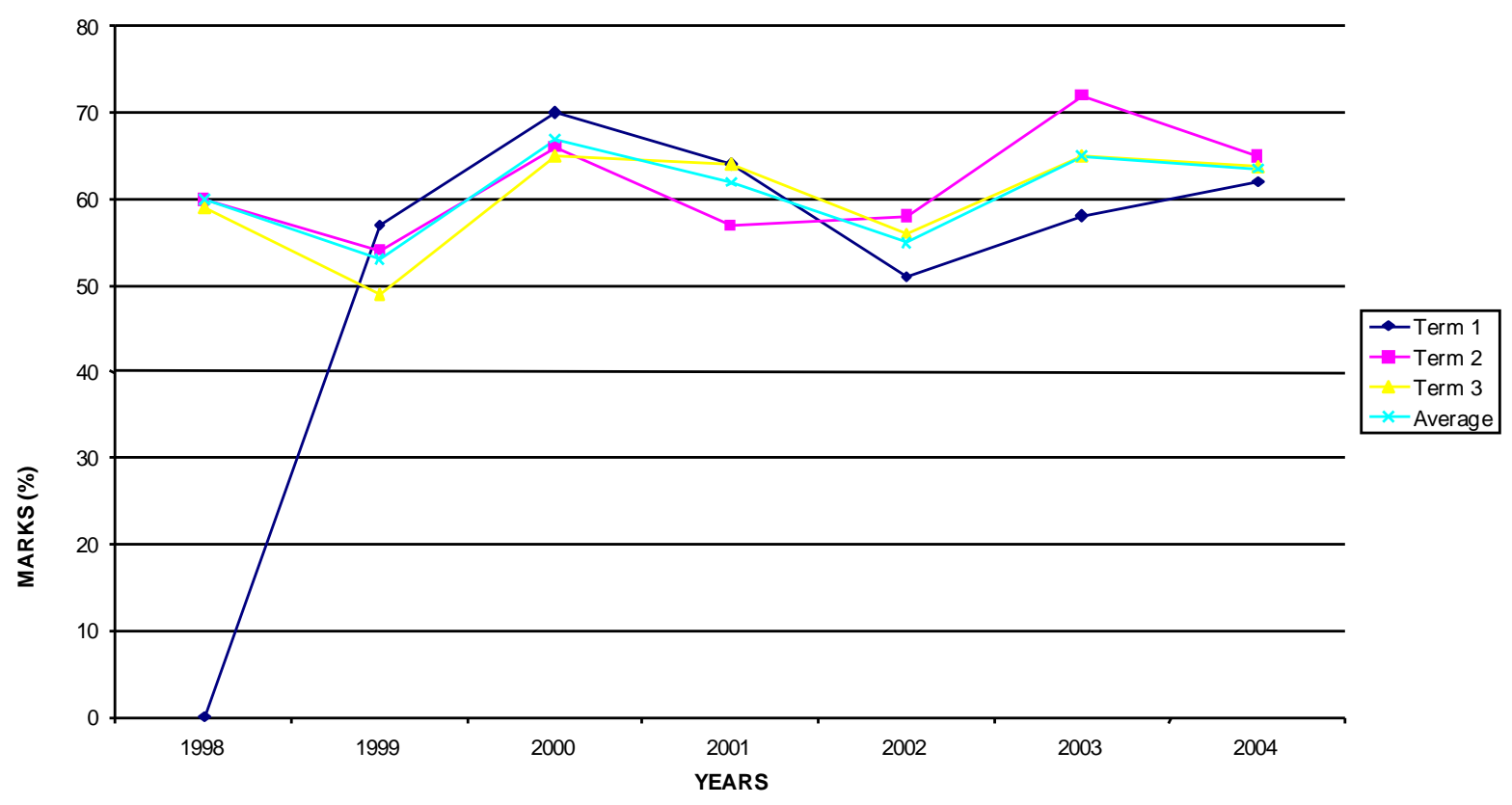

Figure 1. Academic performance 1998-2004.

\section{Discussion}

This case of childhood complex PTSD due to defilement presents one of the major challenges in psychiatry when making a diagnosis in a case which presents with symptoms simulating attention deficit hyperactivity disorder (ADHD), PTSD and rape trauma syndrome (RTS). The patient was initially managed as a case of ADHD and she was treated with methylphenidate (Ritalin) and imipramine (Tofranil) given the overlap of some symptoms between PTSD and ADHD, leading to a decline in hyperactivity and relief in symptoms prior to disclosure about her defilement experience later. She attributed all her psychological problems to the defilement ordeal that she experienced. Though the mother was supportive towards the management of her daughter, she was guarded about her daughter's past history and she did not give the girl the required privacy and freedom of expression during interviews with psychiatrists. It took the patient (young girl) years and a secure interview with a young female final year medical student to reveal the cause of her trauma. The mother wished to brush aside the impact of the trauma on the girl albeit the suffering that the daughter underwent, compelling the girl to seek trust from her grandmother which made her hostile to both the mother and the foster father to the extent of the mother divorcing the husband to save the girl from further trauma. This case once more proved that defilement was always accompanied with deeper and prolonged psychological trauma [1]-[3]. As much as the presentation of PTSD among children often borders on ADHD and RTS, this case undoubtedly scored highly and clearly for complex PTSD and it demonstrated that PTSD in defilement was more traumatic psychologically than ordinary PTSD in addition to being debilitating and lifelong4, a finding that had been established elsewhere [6]-[9].

The symptomatic presentation of this patient closely resembled those of other victims of defilement in other countries [10] [11] and like findings in the United States of America, only 25.0\% - 40.0\% of the victims reported their experiences and sought mental health care mainly among the white women, but African Americans preferred confiding in their relatives and friends. This behaviour was established in this case, in which the patient attempted to confide in the mother, failure to which she did so in the grandmother and strongly bonded with her. She did not gain access to gynaecological and sexually transmitted diseases care and support. It is therefore, recommended that alongside the legal and medical care of victims of defilement, the need for mandatory psychiatric health care is necessary to reduce the prolonged suffering of patients, especially children, given the low rate at which defilement were reported and effective health care sought [12]-[14]. The patient met the DSM IV-TR (2002) criteria for PTSD which qualified her case as complex due to intensity and wide range of symptoms exhibited. The likelihood of lifelong presence of PTSD in this patient was demonstrated by the persistence of the condition for the last three years prominently with impairment in the social and occupational 
functioning in her life. Re-assessment of the patient three years later revealed remarkable improvement on most fronts following the breakthrough in making the appropriate diagnosis. This improvement was a direct product of management of the patient using standard protocol for complex PTSD, a category into which this patient fitted well [15]-[18].

In summary, this case represented others of childhood complex PTSD that went undiagnosed and sometimes misdiagnosed due to the overlap of its symptoms with those of ADHD and RTS and subsequent mismanagement. Detailed history taking, concerted and regular management, team work, effective social support system, intensive and strong follow up programmes, sensitivity to age and sex, accurate classification of PTSD, adherence to ethical requirements and the standard management protocol were found to have been the cornerstones of management of this case, but prognosis will be depend more on the patient's social functioning.

\section{Conclusion}

This case provides us with the opportunity to appreciate that many children are defiled in silence at their psychological and developmental expense. It further creates awareness about the need for mental health and health care providers to go an extra mile during assessments and examinations to dig into the child's sexual status as a possible contribution towards more expose and deterrent to episodes of defilements. This case highlights the need for family members and health care providers to handle children with love and professional and parental touch to enable children to safely open up and seek timely care and support. This case demonstrated that defiled children suffer deeper psychological trauma (complex PTSD) which clearly demonstrated that the same children became dysfunctional while suffering in silence. This case, which was closely followed up (every month for over two years), also demonstrated that dedicated comprehensive health care backed by effective social support system can lead to recovery. It also demonstrated that the children needed definitive treatment and rehabilitation programmes for recovery. The treatment programme must include the element of sensitivity to the children's needs, mandatory screening for defilement and child-friendly settings.

\section{Acknowledgements}

Appreciation and thanks to Ms. Silvia Shitsama, a 2004 final year medical student whose interview with the patient led to revelation about the defilement experience by the patient and her mother, for her tireless and prompt responses to the patient's follow up schedules.

\section{References}

[1] Raine, N.V. (1999) After Silence: Rape and My Journey Back. Crown Publishing Group, 56.

[2] Bergen, R.K. (1996) Wife Rape: Understanding the Response of Survivors and Service Providers. Sage, Thousand Oaks. http://dx.doi.org/10.4135/9781483327624

[3] Russell, D.E.H. (1990) Rape in Marriage. Macmillan Press, New York.

[4] Pagelow, M. (1992) Adult Victims of Domestic Violence. Journal of Interpersonal Violence, 7, 87-120. http://dx.doi.org/10.1177/088626092007001008

[5] American Psychiatric Association (2000) Diagnostic and Statistical Manual of Mental Disorders. 4th Edition, Text Revised (DSM IV-TR, 9th Edition, 2002).

[6] National (USA) Center for Post Traumatic Stress Disorder (PTSD).

[7] Silbert, M. (1984) Treatment of Prostitution Victims of Sexual Abuse. In: Stuart, I. and Greer, J., Eds., Victims of Sexual Aggression, van Nostrand Reinhold.

[8] National Crime Victims Survey. Bureau of Justice Statistics, US Department of Justice, 1999.

[9] Burnam, A., Stein, J., Golding, J., Siegel, J., Sorenson, S., Forsythe, A. and Telles, C. (1988) Sexual Assault and Mental Disorders in a Community Population. Journal of Consulting and Clinical Psychology, 56, 843-850. http://dx.doi.org/10.1037/0022-006X.56.6.843

[10] Burgess, A.W. and Holmstrom, L.L. (1979) Adaptive Strategies and Recovery from Rape. American Journal of Psychiatry, 136, 1278-1282.

[11] Katz, B.L. (1991) The Psychological Impact of Stranger versus Non-Stranger Rape on Victims' Recovery. In: Bechhofer, L. and Parrot, A., Eds., Acquaintance Rape: The Hidden Victim, John Wiley and Sons, New York, 251-269.

[12] Golding, J., Stein, J., Siegel, J., Burnam, M. and Sorenson, S. (1989) Sexual Assault History and Use of Health and 
Mental Health Services. American Journal of Community Psychology, 16, 625-643. http://dx.doi.org/10.1007/BF00930018

[13] Campbell, R. (1998) The Community Response to Rape: Victims’ Experiences with the Legal, Medical, and Mental Health Systems. American Journal of Community Psychology, 26, 355-379. http://dx.doi.org/10.1023/A:1022155003633

[14] Wyatt, G.E. (1992) The Sociocultural Context of African American and White Women's Rape. Journal of Social Issues, 48, 77-92. http://dx.doi.org/10.1111/j.1540-4560.1992.tb01158.x

[15] Foa, E.B., Rothbaum, B.O. and Molnar, C. (1995) Cognitive-Behavioural Therapy of PTSD. In: Friedman, M.J., Charney, D.S. and Deutch, A.Y., Eds., Neurobiological and Clinical Consequences of Stress: From Normal Adaptation to PTSD, Raven Press, New York.

[16] Friedman, M.J. and Southwick, S.M. (1995) Towards Pharmacotherapy for PTSD. In: Friedman, M.J., Charney, D.S. and Deutch, A.Y., Eds., Neurobiological and Clinical Consequences of Stress: From Normal Adaptation to PTSD, Raven Press, New York.

[17] Friedman, M.J. (1996) PTSD Diagnosis and Treatment for Mental Health Clinicians. Community Mental Health Journal, 32, 173-189. http://www.dartmouth.edu/dms/ptsd/Clinicians.html. http://dx.doi.org/10.1007/BF02249755

[18] National Center for PTSD Fact Sheet, 2001 (United States of America).

[19] American Psychiatric Association (2002) Diagnostic and Statistical Manual of Mental Disorders. 4th Edition, Text Revised (DSM IV-TR).

[20] OPNAVINST 1752.1A, Sexual Assault Victim Intervention (SAVI) Program, SECNAV 1752.4.

[21] Magley, V. (2002) Coping with Sexual Harassment: Re-Conceptualizing Women's Resistance. Journal of Personality and Social Psychology, 83, 930-946. http://dx.doi.org/10.1037/0022-3514.83.4.930

[22] http://www.nowldef.org/html/njep/medicalevidence resources.shtml\#sex 
Scientific Research Publishing (SCIRP) is one of the largest Open Access journal publishers. It is currently publishing more than 200 open access, online, peer-reviewed journals covering a wide range of academic disciplines. SCIRP serves the worldwide academic communities and contributes to the progress and application of science with its publication.

Other selected journals from SCIRP are listed as below. Submit your manuscript to us via either submit@scirp.org or Online Submission Portal.
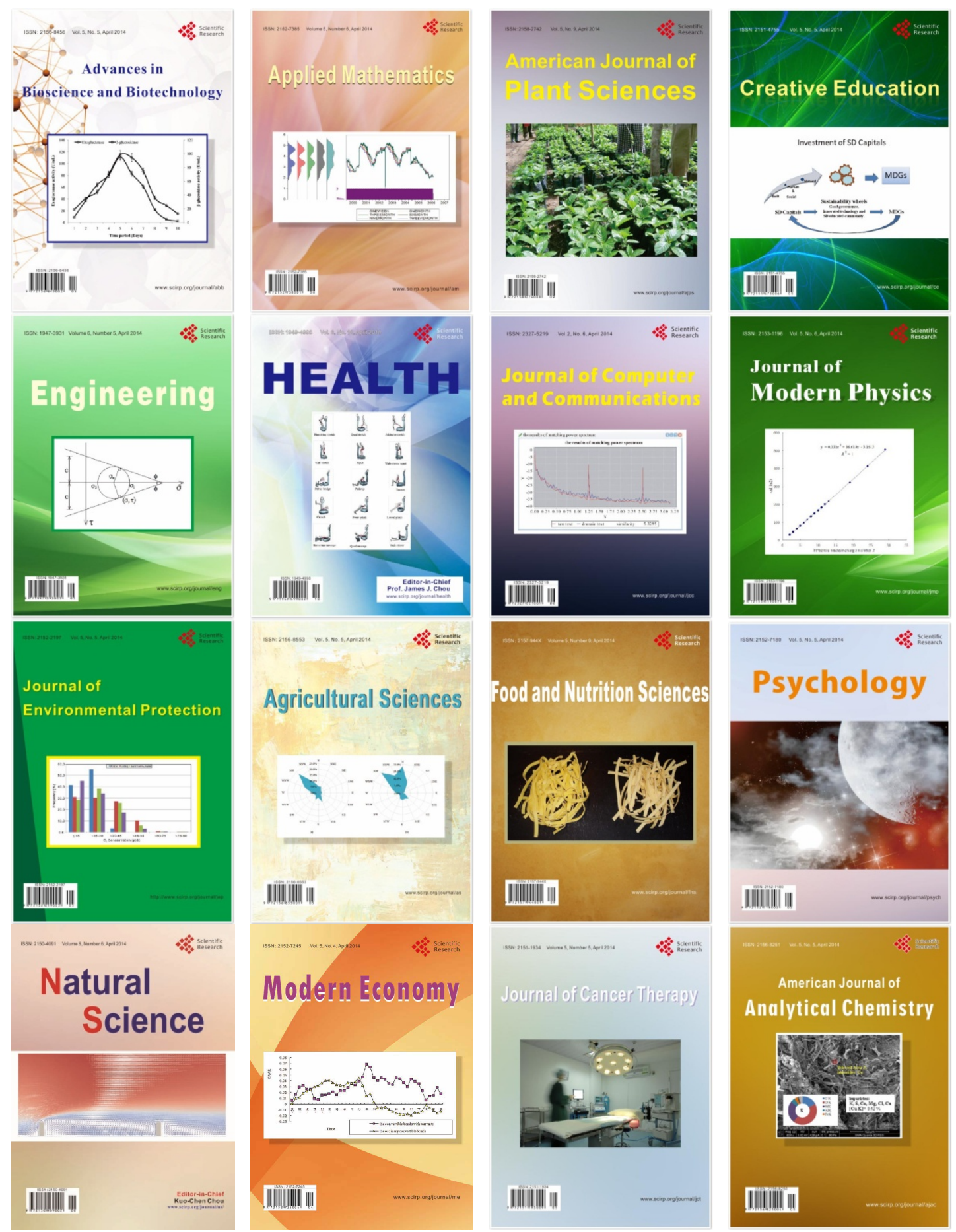